\title{
Characterization of PI (breast cancer cell special peptide) in MDA-MB-231 breast cancer cells and its potential therapeutic applications
}

\author{
CHANGE GAO ${ }^{1}$, MIN HONG $^{1}$, JIWEI GENG ${ }^{1}$, HUAHUA ZHOU $^{1}$ and JIAN DONG ${ }^{2}$ \\ ${ }^{1}$ Medical Oncology, The First Affiliated Hospital of Kunming Medical University, Kunming, Yunnan 650032; \\ ${ }^{2}$ Medical Oncology, The Third Affiliated Hospital of Kunming Medical University, Kunming, Yunnan 650018, P.R. China
}

Received June 12, 2015; Accepted July 23, 2015

DOI: $10.3892 /$ ijo.2015.3140

\begin{abstract}
Gene therapy is one of the most important aspects of molecular targeted therapeutic approaches for tumors. A small molecule targeting carrier plays an important role in this process. PI, a new peptide found in our phage library, has been specifically suggested, combined with the human triple-negative breast cancer cell line MDA-MB-231, and may be developed as a targeting/individualization therapy strategy to be applied in breast cancer research. In this study, we further investigated whether this peptide could carry exogenous protein to the target cells by forming a fusion peptide. PI-GST and PI-TK were cloned into plasmids and used for expression studies, analyses of PI-mediated protein delivery efficiency, and to investigations into the effect of PI on thymidine kinase/ganciclovir-mediated cytotoxicity. Biodistribution profiles were also investigated in vivo. The results showed the PI fusion protein was expressed correctly in vitro, and could carry GST into the target cells. Under certain conditions, PI-TK sensitizes cells to ganciclovir more efficiently than TK. In vivo there was a trend for increased inhibition of tumor growth with PI-TK when ganciclovir was present. Therefore, our results suggest the potential of PI as a new specific target carrier in breast cancer therapy.
\end{abstract}

\section{Introduction}

Breast cancer is the most common cancer in female adults worldwide (1) and the second leading cause of cancer death (2). It has become the greatest threat to women in our country. Triple-negative breast cancer (TNBC), which is negative for estrogen, progesterone and HER-2/neu receptors, has recently been identified in certain sub-groups of patients, and has the highest recurrence rate, fast growth and poorest

Correspondence to: Dr Jian Dong, Department of Oncology, The Third Affiliated Hospital of Kunming Medical University, 519 Kunzhou Road, Kunming, Yunnan 650018, P.R. China

E-mail: dongjian181818@sina.com

Key words: PI, breast cancer, targeted therapy, HSV-TK/GCV prognosis (3). It represents up to $20 \%$ of all breast cancers and currently has no standard treatment (4). In the past five years, evidence has emerged indicating that TNBC is associated with the inactivation of BRCA1 and overexpression of epidermal growth factor receptor (EGFR), which makes it sensitive to anti-EGFR therapies (5). Additionally, novel molecular-targeted treatments focusing on tyrosine kinase inhibitors (TKI) (6), anti-angiogenesis [vascular endothelial growth factor (VEGF) antibody] (7), and the key enzymes of cellular DNA repair such as poly-ADP ribose polymerase 1 (PARP1) $(8,9)$, have been developed but are still undergoing trials. Therefore, the development of new, highly effective and targeted carrier systems to transfer bioactive substances directly into tumor cells is one feasible method for tumor targeting therapy.

Over the past decade, some peptides with lengths less than 30 amino acids have been found, which are named 'cell penetration peptides' (CPP) (10). They have the ability to penetrate the cell membrane or nuclear membrane and become localized in the cytoplasm or nucleus after internalization. They can carry a variety of materials without limited cell types, including hydrophilic proteins, polypeptides, DNA and even particulate matter, such as spaces between cells or intracellular delivery (11). In a previous study, we found an 11 amino acid peptide named 'PI', which was selected from the pC89 phage display library. In the sequence of PI, nonpolar hydrophobic amino acids constitute the majority, with a samller proportion of basic amino acids. The characteristics of this peptide are different from those of most classical cell penetrating peptides. We also found that PI is especially targeting breast cancer, and not other cancer cells or noncancer cells (12). This finding suggests that PI could be a potential discovery useful in breast cancer cell therapy.

In this study, we demonstrate the value of PI as a targeting vector to deliver therapeutic molecules including chemotherapy drugs, proteins or polynucleotides in breast cancer therapy, especially in triple-negative breast cancer therapy.

\section{Materials and methods}

Peptide synthesis and radiolabelling of HYNIC-PI. PI (CASPSGALRSC) was synthesized with a cysteine terminal. 
For biodistribution, radiolabeling of HYNIC-PI was performed by mixing $\sim 20 \mu \mathrm{g}$ of HYNIC with $15 \mu \mathrm{l}$ of tricine $(100 \mathrm{mg} / \mathrm{ml}$ in citrate buffer, $20 \mathrm{mM}$ citrate, $100 \mathrm{mM} \mathrm{NaCl}, \mathrm{pH}$ 5.2), $100 \mu \mathrm{l}$ of TPPTS and $\sim 1.85 \mathrm{MBq}$ of $\mathrm{TcO}_{4}^{-}$, mixed in nitrogen, reaction at $100^{\circ} \mathrm{C}$ for $25 \mathrm{~min}$, then cooled down. The resulting reaction mixture was purified by HPLC using a BioSep 2000 column eluted with PBS (0.01 mM Na $\left.\mathrm{mPO}_{4}, 100 \mathrm{mM} \mathrm{NaCl}, \mathrm{pH} 7.4\right)$ and the radiochemical purity of the final product was $>95 \%$.

Cell culture. Approximately 25,000-30,000 adherent MDA-MB-231 cells were cultivated in 24-well tissue plate for $12 \mathrm{~h}$ in Lei Ovitz's (L-15), supplemented with HEPES (25 mM), penicillin/streptomycin (1\%), fetal serum $(10 \%)$, and L-glutamine in a $5 \% \mathrm{CO}_{2}$ humidified atmosphere at $37^{\circ} \mathrm{C}$. Approximately 25,000-30,000 adherent MDA-MB-435 cells were cultivated in a 24-well tissue plate for $12 \mathrm{~h}$ in PRMI-1640 supplemented with HEPES $(25 \mathrm{mM})$, penicillin/streptomycin (1\%), fetal serum (10\%), and L-glutamine in a $5 \% \mathrm{CO}^{2}$ humidified atmosphere at $37^{\circ} \mathrm{C}$. All products were purchased from Gibco (CA, USA).

Construction and expression of vectors. Oligonucleotide PI encoding region (sequence: 5' TGCGCATCCCCATCTGG CGCCCTTCGTTGTTGC 3') was synthesized by Invitrogen Ltd. (Shanghai, China). Then, the duplexes were cloned into the BamHI/EcoRI sites of pGEX-2T.

Similar to the above process, we constructed the pET-28a (+)-PI. We used the primers to amplify TK gene fragments from the HSV1-TK plasmid as a template. The PCR products were digested with EcoRI/SalI, and subcloned into pET-28a (+)-PI and pET-28a (+) to generate the plasmids pET-28a (+)-PI-TK and pET-28a (+)-TK, respectively. All vectors were purchased from Invivogen (CA, USA), and all enzymes were purchased from Takara (Dalian, China). Non-recombinant pGEX-2T was used to produce GST as a control protein.

Recombinant plasmids were identified by single restriction enzyme digestion and analyzed by SDS-PAGE electrophoresis. E. coli strain BL21 (DE3) was transformed with the recombinant plasmids or vector alone, and then grown in LB broth containing $100 \mu \mathrm{g} / \mathrm{ml}$ ampicillin at $37^{\circ} \mathrm{C}$. Isopropyl- $\beta$-D-thiogalactopyranoside (IPTG) was added to a final concentration of $1 \mathrm{mM}$, and incubation was continued at $37^{\circ} \mathrm{C}$ for 1-6 h. After IPTG induction, bacteria pellets were obtained by centrifugation at $3500 \mathrm{rpm}$. The supernatant was collected and stored at $-80^{\circ} \mathrm{C}$ for use with western blotting.

Purification of the fusion proteins. PI-GST fused protein products in the supernatant fraction were purified on a GST-sepharose columns. Purification was carried out essentially as described by the manufacturer. Briefly, $100 \mathrm{ml}$ of sample was centrifuged to remove any undissolved membranes and cellular debris before being applied to the column. Triton X-100 was then added to the collected supernatants. The column was washed with 5-10 volumes of PBS to remove azide and equilibrated with 3-5 volumes of PBS containing $1 \%$ Triton X-100. Then, the sample was applied to the prepared column. The flowthrough was collected as a control. The column was washed with 10 volumes of PBS until eluted and no protein could be detected. The
PI-TK fusion proteins were purified using a His TALON ${ }^{\mathrm{TM}}$ Cartridge Purification kit (Clontech, USA). The purified proteins were run on $12 \%$ SDS-polyacrylamide gels.

Immunofluorescence. MDA-MB-231 and MDA-MB-435 $\left(1 \times 10^{5}\right)$ cells were incubated with $200 \mathrm{ng} / \mathrm{ml}$ of PI-GST in culture medium for $8-12 \mathrm{~h}$ at $37^{\circ} \mathrm{C}$, and washed six times with PBS. Then, the cultured cells were fixed in $10 \%$ Triton X-100 for $10 \mathrm{~min}$, and detected by 30-min incubation with FITCconjugated mouse monoclonal antibody (anti-GST-FITC) (Santa Cruz). The cells were then washed twice with PBS and immediately observed by fluorescence microscopy. The cells were incubated with GST alone as a control. Non-recombinant pGEX4T-1 was used to produce GST as a control protein.

Western blot analysis. MDA-MB-231 and MDA-MB-435 were seeded onto 6 -well plates at a density of $2 \times 10^{5}$ cells/well, and treated with recombinant protein. Twenty-four hours later, the cells were trypsinized with trypsin-EDTA (Gibco BRL, Life Technologies, UK) and washed once with phosphate-buffered saline (PBS). Total cell lysis buffer (Beyotime, China) was added to cell pellets and the cells were incubated on ice for $30 \mathrm{~min}$. Proteins were extracted and $30 \mu \mathrm{g}$ of total protein was loaded on a $12 \%$ SDS-polyacrylamide gel, followed by electrophoretic separation of the proteins and transfer to PVDF membrane (Millipore, USA). The membrane was blocked for $1 \mathrm{~h}$ in $10 \%$ skim milk, and reacted with 1:1,000 diluted anti-His or 1:1,000 anti-GST for $1 \mathrm{~h}$ at $37^{\circ} \mathrm{C}$. The membrane was then incubated with goat anti-mouse $\operatorname{IgG}(\mathrm{H}+\mathrm{L})$, HRP conjugated secondary antibody (1:2,000, Santa Cruz). Chemiluminescence detection was carried out using an ECL Plus Western Blotting Detection system (Amersham Biosciences) according to the manufacturer's instructions.

Cell proliferation assay. Cell viability was determined using the Cell Counting kit- 8 (CCK-8) cell proliferation assays according to the manufacturer's instructions (Beyotime). Briefly, MDA-MB-231 or MDA-MB-435 cells were plated in three 96-well microplates in $200 \mu \mathrm{l}$ of medium, and co-cultured with PI-TK fusion protein $(0,40,80,120,160$ and $200 \mu \mathrm{g} / \mathrm{ml}$ ), and then supplemented with $10 \mathrm{mg} / 1$ ganciclovir (GCV) the following day. After $48 \mathrm{~h}, 20 \mu \mathrm{l}$ of CCK8 substrate was added into each well, and the palates were returned to standard tissue incubator conditions for an additional $1 \mathrm{~h}$. The medium was then removed, the cells were solubilized in $150 \mu \mathrm{l}$ of dimethyl sulfoxide, and colorimetric analysis was performed (wavelength, $450 \mathrm{~nm}$ ). The inhibition rate was calculated as [1- (OD value of the transfection/OD value of untreated cells)] x $100 \%$. Each experiment was performed in triplicate. TK protein was added into the cells as a control under the same experiment conditions and the procedure was repeated twice.

Cytotoxicity assay. Human breast carcinoma MDA-MB-231 cells were grown in Lei Ovitz's (L-15) supplemented with $10 \%$ fetal born serum (Life Technologies, Inc.) containing penicillin $(100 \mathrm{U} / \mathrm{ml})$ and streptomycin $(100 \mu \mathrm{g} / \mathrm{ml})$. All of the cultures were maintained in a $37^{\circ} \mathrm{C}$ incubator with $5 \% \mathrm{CO}_{2}$ in air. The cells were plated in Costar 24-well culture plates at a density of $2 \times 10^{3}$ cells/well. The cells were treated with 


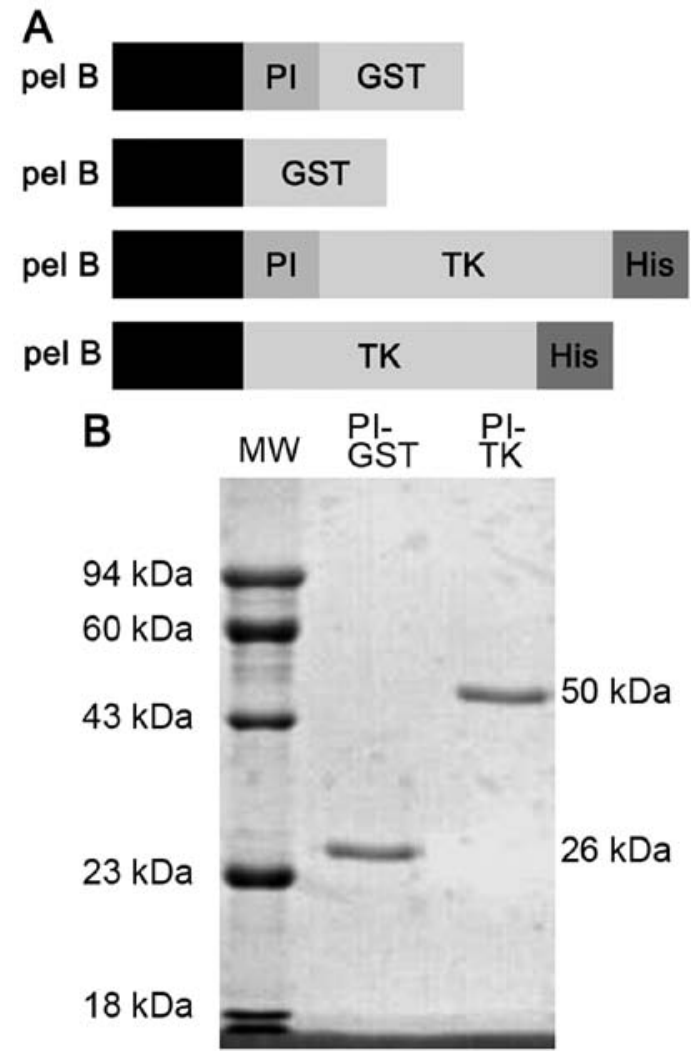

Figure 1. PI fusion proteins. (A) Schematic representation of PI fusion constructs in GST or HIV-1-based lentiviral vector backbone; herpes virus type 1 (HSV-1) tegument protein PI, HSV-1 thymidine kinase (TK), cytomegalovirus promoter (CMV), long terminal repeats (LTR), base pairs (bp) (B) $12 \%$ SDS-polyacrylamide gel analysis of purified recombinant PI-GST and PI-TK.

different amounts of purified recombinant proteins for 6 days, and the cytotoxicity was determined using the CCK8 method, as described above.

Persistent killing effect assay. MDA-MB-231 cells were treated with $200 \mu \mathrm{g} / \mathrm{ml}$ of PI-TK, or TK as a control for $4 \mathrm{~h}$, and then washed with fresh medium and cultured in regular medium. The cells were subcultured every 3 days, and samples were exposed to $10 \mu \mathrm{g} / \mathrm{ml} \mathrm{GCV}$ at intervals. The viability was assessed for 15 days, and determined using the CCK8 method, as described above.

Biodistribution and SPECT imaging in mice. The biodistribution analysis studies were carried out in $30 \mathrm{BALB} / \mathrm{c}$ mice (4-6-week-old, weighing 20-22 g, purchased from the Third Military Medical University, Chongqing, China). ${ }^{99 m}$ Tc-HYNIC-PI was injected into 30 mice via the tail vein. Mice were divided into 6 groups and samples were obtained $30 \mathrm{~min}, 1,2,4$ and $6 \mathrm{~h}$ after injection of $100 \mu \mathrm{l}$ of radiotracer. All the groups were dynamically imaged using Millennium ${ }^{\mathrm{TM}}$ MPR SPECT. At each time-point, a 200- $\mu$ l blood sample was taken from the suborbital sinus of non-anaesthetized mice. Immediately after obtaining this blood sample the animals were euthanized by cervical dislocation and the main organs were dissected and counted in a gamma counter. The injection dose rate (\% of ID/g) and tumor/non tumor tissue radioactivity
(T/NT) ratio were calculated. All the animal studies were conducted according to the international standard and the ethics approval was granted by Ethics Committee of Kunming Medical University, P.R. China.

Statistical analyses. The efficacy of the two treatment groups was compared by Student's t-test. In cases of more than two variable groups, two-way ANOVA and Bonferroni's post hoc test were used (GraphPad Prism 6.0, GraphPad Software Inc., San Diego, CA, USA).

\section{Results}

Expression and identification of fusion proteins in vitro. The recombinant prokaryotic expression plasmids pGEX-2T, pGEX-2T-PI, pET-28a (+)-PI-TK and pET-28a (+)-TK, were first characterized by EcoRI and BamHI, EcoRI and SalI, restriction enzyme digestion, respectively, in accordance with the size of the target DNA, with no shift and no mutation (Fig. 1A). Then, PI-GST and PI-TK purified proteins were analyzed on a $12 \%$ SDS-polyacrylamide gel. Single bands corresponding to molecular masses of 26 and $50 \mathrm{kDa}$ were observed, which were inconsistent with the theoretical values (Fig. 1B).

Delivery location and efficiency of PI in target cells. At the optimal peptide concentration of $200 \mathrm{mg} / \mathrm{ml}$, PI-GST was efficiently uptaken by MDA-MB-231 cells. In the initial $12 \mathrm{~h}$ of culturing, PI-GST gave strong staining mainly on the cell membrane, but also showed substantial intracellular staining. After $24 \mathrm{~h}$, the intracellular PI/GST signal was observed in the nucleus. Forty-eight hours later, the signal of fusion proteins in cells weakened and disappeared. Compared to MDA-MB-231 cells, the intracellular fluorescence of PI-GST was not detected in MDA-MB-435 cells under the microscope (Fig. 2A).

To determine the PI delivery efficiency, we incubated PI-GST or PI-TK, with breast cancer cells, and performed immunoblotting with anti-GST and anti-His antibody (Fig. 2B). The results showed that PI fusion proteins were expressed at detectable levels, but the expression of non-PI fusion proteins was not observed.

The cell type-specific killing effect of PI-TK in the presence of $G C V$. To evaluate the cell-killing efficiency in vitro, we co-cultured MDA-MB-231 or MDA-MB-435 cells with PI-TK fusion protein with for $48 \mathrm{~h}$ at various concentrations and then treated the cells with GCV. The cell viability results showed that the proliferation rate of attached cells in the PI-TK and TK groups gradually increased and that the cell growth inhibition rate in the PI-TK group was higher than that in the TK group (Fig. 3A). As a control, the growth of MDA-MB-435 cells treated with PI-TK or TK was significantly inhibited under the same experimental conditions. However, no difference in MDA-MB-435 cell proliferation was observed between the PI-TK and TK groups (Fig. 3B).

Second, we performed the following experiments using MDA-MB-231 and MDA-MB-435 lines. First, both cell types were treated with recombinant proteins PI-TK, PI, and TK for $4 \mathrm{~h}$. Then, each set of treated cells was divided into two parts: one part was extensively washed with the regular medium 


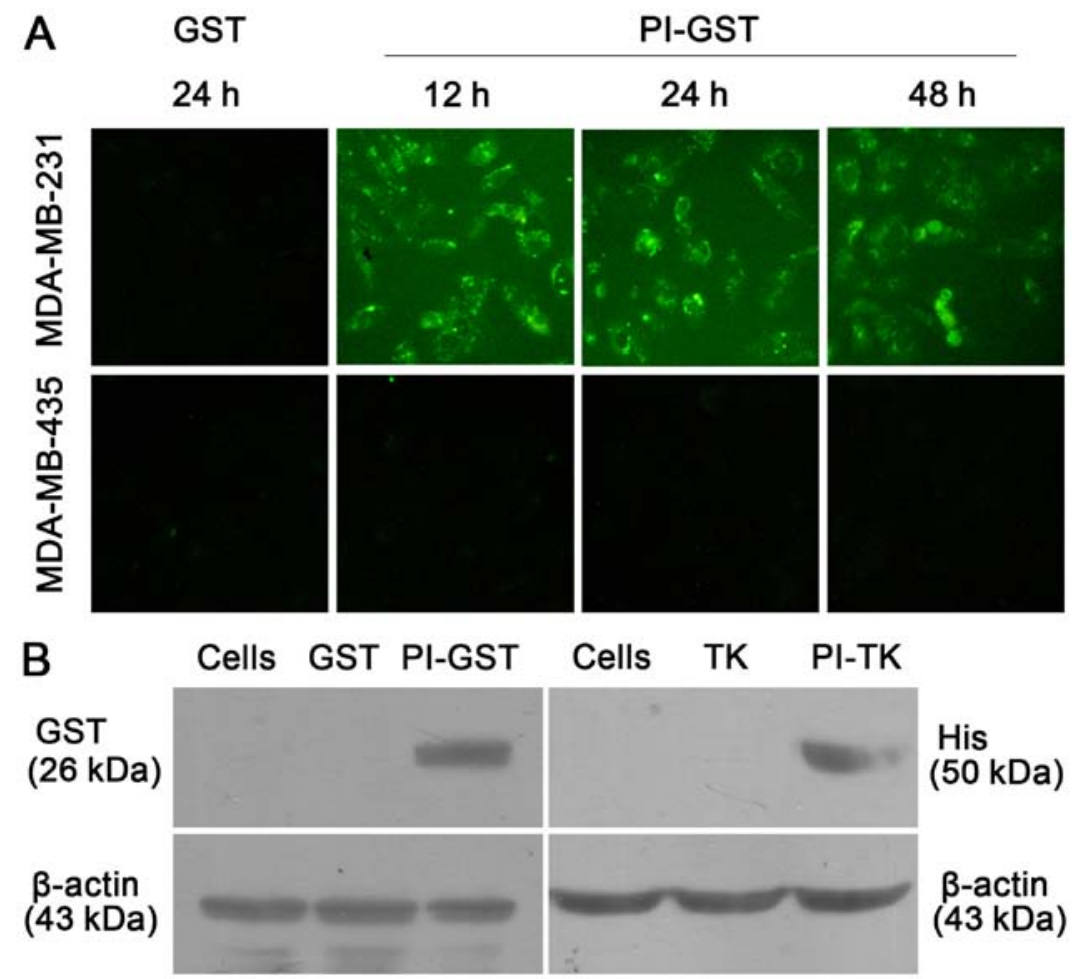

Figure 2. Transduction and location of recombinant PI fusion protein. (A) Intracellular distribution of transduced PI-GST in MDA-MB-231 and MDA-MB-435 cells. Cells incubated with GST followed by anti-GST (C-term)-FITC as a control. (B) Verification of full-length fusion protein expression in vitro in MDA-MB-231 human breast cancer cells detected by western blotting using an anti-GST or anti-His antibody.

MDA-MB-231 cells
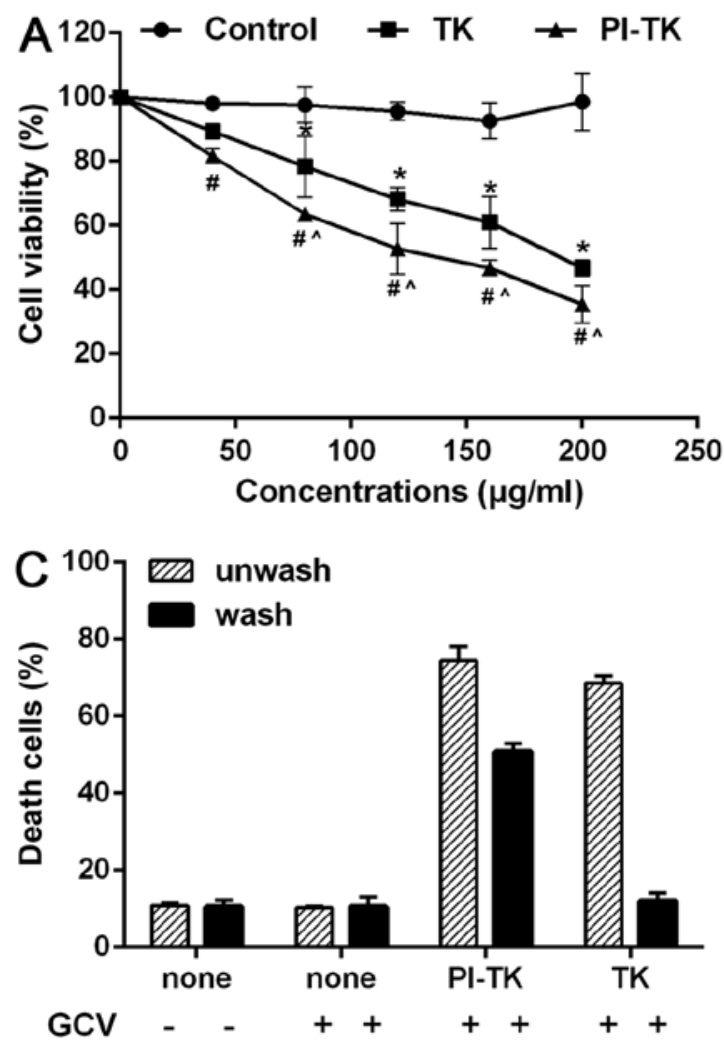

MDA-MB-435 cells
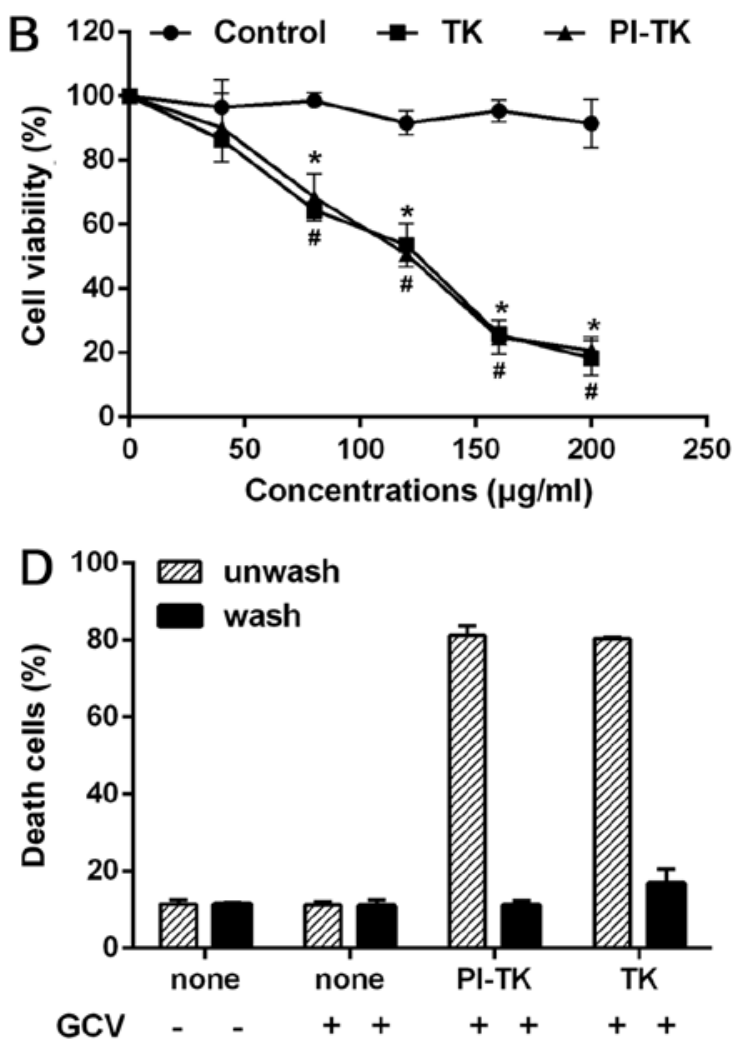

Figure 3. Effects of PI-peptide on HSV-TK/GCV-mediated cell killing in different human breast cancer cells. Different concentration of TK and PI-Tk mediated cell killing in MDA-MB-231 (A) and MDA-MB-435 cell lines (B). Viability of cells containing 20\% of PI-TK or TK expressing cells compared with non-transduced cells after 48-h treatment with various GCV concentrations (10 $\mu \mathrm{g} / \mathrm{ml})$. MDA-MB-231 (C) and MDA-MB-435 cells (D) were incubated with PI-TK or TK alone for $4 \mathrm{~h}$. Each culture was then divided into two sets: one set was washed extensively with regular medium and grown in regular medium containing GCV, and other set of cells was not washed and maintained in the same medium containing GCV. Cell viability was counted 4 days later; bars, \pm SD. 

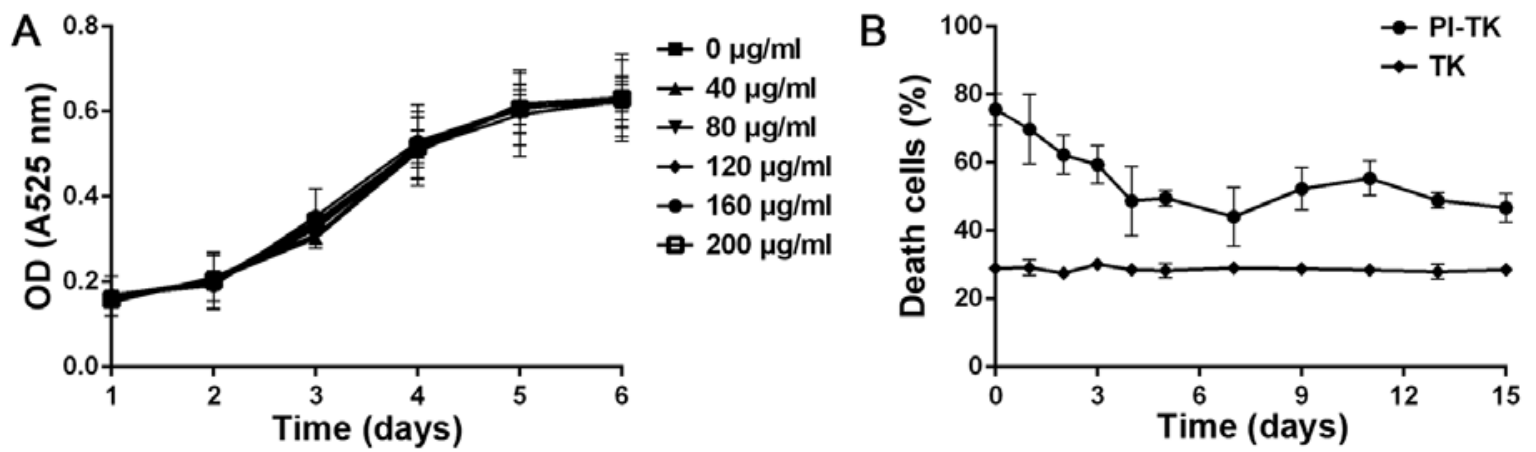

Figure 4. Persistent effect of PI-TK on cell killing of MDA-MB-231 cells. (A) Cytotoxicy of PI-TK at different concentrations $(0-200 \mu \mathrm{g} / \mathrm{ml})$ identified by CCK8 method. (B) Stability of internalized PI-TK. MDA-MB-231 cells were incubated with PI-TK for $4 \mathrm{~h}$ and then washed with fresh medium and cultured in regular medium for 15 days. The cells were exposed to $10 \mu \mathrm{g} / \mathrm{ml} \mathrm{GCV}$ at intervals and mortality was assessed. TK-treated cells were used as a control. Each point represents the average of three independent experiments; bars, \pm SD.

Table I. Radioactivity uptake of ${ }^{99} \mathrm{Tc}^{\mathrm{m}}$-(HYNIC-PI) (tricine) (TPPTS) in normal mouse at each time point (mean $\pm \mathrm{SD}, \mathrm{n}=5$, $\% \mathrm{ID} / \mathrm{g})$.

\begin{tabular}{lcccccccr}
\hline & \multicolumn{7}{c}{ Time } \\
\cline { 2 - 9 } Organ & $1 \mathrm{~min}$ & $5 \mathrm{~min}$ & $10 \mathrm{~min}$ & $30 \mathrm{~min}$ & $1 \mathrm{~h}$ & $2 \mathrm{~h}$ & $4 \mathrm{~h}$ & $6 \mathrm{~h}$ \\
\hline Heart & $2.20 \pm 0.23$ & $1.31 \pm 0.17$ & $0.96 \pm 0.35$ & $0.42 \pm 0.15$ & $0.41 \pm 0.14$ & $0.22 \pm 0.02$ & $0.18 \pm 0.03$ & $0.12 \pm 0.08$ \\
Liver & $1.21 \pm 0.72$ & $0.83 \pm 0.08$ & $0.69 \pm 0.24$ & $0.31 \pm 0.10$ & $0.25 \pm 0.03$ & $0.19 \pm 0.03$ & $0.11 \pm 0.02$ & $0.08 \pm 0.03$ \\
Lung & $4.6 \pm 0.84$ & $2.63 \pm 0.37$ & $2.41 \pm 0.58$ & $0.82 \pm 0.24$ & $0.69 \pm 0.16$ & $0.37 \pm 0.01$ & $0.30 \pm 0,02$ & $0.22 \pm 0.09$ \\
Kidney & $7.72 \pm 0.94$ & $9.33 \pm 0.33$ & $10.31 \pm 4.00$ & $10.75 \pm 2.24$ & $13.53 \pm 2.47$ & $13.57 \pm 1.79$ & $14.83 \pm 1.48$ & $11.23 \pm 1.34$ \\
Spleen & $1.22 \pm 0.36$ & $1.05 \pm 0.19$ & $0.85 \pm 0.10$ & $0.47 \pm 0.14$ & $0.41 \pm 0.08$ & $0.29 \pm 0.04$ & $0.17 \pm 0.06$ & $0.14 \pm 0.13$ \\
Stomach & $1.00 \pm 0.45$ & $0.51 \pm 0.22$ & $0.48 \pm 0.30$ & $0.16 \pm 0.04$ & $0.14 \pm 0.03$ & $0.10 \pm 0.04$ & $0.11 \pm 0.04$ & $0.09 \pm 0.05$ \\
Bone & $1.34 \pm 0.13$ & $1.21 \pm 0.60$ & $1.08 \pm 12.10$ & $0.69 \pm 0.16$ & $0.44 \pm 0.30$ & $0.21 \pm 0.02$ & $0.23 \pm 0.07$ & $0.20 \pm 0.14$ \\
Muscle & $1.11 \pm 0.16$ & $1.15 \pm 0.12$ & $0.80 \pm 0.41$ & $0.35 \pm 0.10$ & $0.24 \pm 0.11$ & $0.16 \pm 0.04$ & $0.15 \pm 0.05$ & $0.11 \pm 0.12$ \\
Gastric & $1.49 \pm 0.24$ & $1.46 \pm 0.28$ & $1.14 \pm 0.44$ & $0.37 \pm 0.12$ & $0.35 \pm 0.23$ & $0.17 \pm 0.03$ & $0.12 \pm 0.02$ & $0.09 \pm 0.06$ \\
Blood & $2.53 \pm 0.61$ & $2.27 \pm 0.13$ & $1.75 \pm 0.35$ & $1.45 \pm 0.44$ & $0.46 \pm 0.17$ & $0.23 \pm 0.03$ & $0.17 \pm 0.03$ & $0.13 \pm 0.07$ \\
\hline
\end{tabular}

to remove the recombinant proteins, and the other part was not. The cells in both parts were then treated with GCV. As expected, unwashed MDA-MB-231 cells treated with PI-TK or TK alone were sensitive to the subsequent GCV treatments (Fig. 3C, hatched bars). In the washed cultures, only PI-TK-pretreated cells were sensitive to the GCV treatment (Fig. 3C, solid bars). In similar experiments with MDA-MB435 (Fig. 3D), the removal of PI-TK or TK from the treated cells failed to induce cell death upon the subsequent addition of GCV.

These results suggested that PI-TK could be taken up specially by MDA-MB-231 cells and exerted cell-killing activity.

Cytotoxicity and stability of internalized PI-TK. Herpes simplex virus thymidine kinase (HSV-TK)/GCV system was delivered into tumor cells to test its killing effect. To exclude the cytotoxicity and confirm adherence of the fusion protein, PI-TK, we incubated the fusion protein with MDA-MB-231 alone. The results of the CCK- 8 methods revealed that this system was non-cytotoxic to cells, as shown in Fig. 4A.
To determine the stability of PI-TK, we carried out cell-killing experiments. MDA-MB-231 cells were treated with $200 \mu \mathrm{g} / \mathrm{ml}$ of PI-TK or TK for $4 \mathrm{~h}$ then the recombinant proteins were removed, and the cells were cultured in fresh medium. The proliferation was detected at different times after treating with GCV for 15 days. The sustained cell-killing was observed in the PI-TK-treated cells, even at 15 days, and only the basal level of cell death $(\mathrm{t}<10 \%)$ was observed in TK-treated cells (Fig. 4B). This observation supports the sustained stability of the recombinant PI fusion protein.

Biodistribution and SPECT imaging of ${ }^{99 m}$ Tc-HYNIC-PI. The biodistribution and metabolization in normal mice and nude mice bearing human breast cancer cells MDA-MB-231 were investigated in this study. The biodistribution of PI in normal mice indicated that the blood radioactivity decreases $[(1.45 \pm 0.44) \% \mathrm{ID} / \mathrm{g}]$ at $30 \mathrm{~min}$ and that ${ }^{99 \mathrm{~m}} \mathrm{Tc}-\mathrm{HYNIC}-\mathrm{PI}$ was cleared rapidly thereafter. The physiological uptakes of the kidney $[(14.83 \pm 1.48) \% \mathrm{ID} / \mathrm{g}]$ was the highest at $4 \mathrm{~h}$ and revealed that the radio-pharmaceutical was primarily 
Table II. Radioactivity uptake of ${ }^{99} \mathrm{Tc}^{\mathrm{m}}$-(HYNIC-PI) (tricine) (TPPTS) in tumor bearing mice at each time point (mean \pm SD, $\mathrm{n}=5, \% \mathrm{ID} / \mathrm{g})$.

\begin{tabular}{|c|c|c|c|c|c|}
\hline \multirow[b]{2}{*}{ Organ } & \multicolumn{5}{|c|}{ Time } \\
\hline & $30 \mathrm{~min}$ & $60 \mathrm{~min}$ & $120 \mathrm{~min}$ & $240 \mathrm{~min}$ & $360 \mathrm{~min}$ \\
\hline Heart & $0.43 \pm 0.07$ & $0.49 \pm 0.04$ & $0.32 \pm 0.06$ & $0.21 \pm 0.08$ & $0.15 \pm 0.04$ \\
\hline Liver & $0.63 \pm 0.14$ & $0.67 \pm 0.21$ & $0.61 \pm 0.26$ & $0.29 \pm 0.10$ & $0.28 \pm 0.13$ \\
\hline Lung & $0.91 \pm 0.13$ & $0.82 \pm 0.05$ & $0.69 \pm 0.26$ & $0.36 \pm 0.11$ & $0.19 \pm 0.06$ \\
\hline Kidney & $11.66 \pm 1.01$ & $12.08 \pm 0.98$ & $13.96 \pm 4.68$ & $26.98 \pm 9.31$ & $22.72 \pm 6.84$ \\
\hline Spleen & $0.33 \pm 0.04$ & $0.35 \pm 0.13$ & $0.30 \pm 0.09$ & $0.20 \pm 0.08$ & $0.13 \pm 0.10$ \\
\hline Stomach & $0.24 \pm 0.06$ & $0.36 \pm 0.04$ & $0.31 \pm 0.10$ & $0.28 \pm 0.03$ & $0.26 \pm 0.08$ \\
\hline Bone & $0.44 \pm 0.06$ & $0.61 \pm 0.21$ & $0.56 \pm 0.06$ & $0.42 \pm 0.18$ & $0.33 \pm 0.06$ \\
\hline Muscle & $0.34 \pm 0.06$ & $0.36 \pm 0.04$ & $0.27 \pm 0.09$ & $0.15 \pm 0.04$ & $0.09 \pm 0.02$ \\
\hline Gastric & $0.44 \pm 0.19$ & $0.51 \pm 0.13$ & $0.42 \pm 0.08$ & $0.28 \pm 0.08$ & $0.30 \pm 0.05$ \\
\hline Tumor & $2.48 \pm 0.24$ & $1.46 \pm 0.02$ & $1.40 \pm 0.20$ & $1.38 \pm 0.29$ & $0.67 \pm 0.24$ \\
\hline Blood & $0.88 \pm 0.15$ & $0.81 \pm 0.06$ & $0.48 \pm 0.04$ & $0.25 \pm 0.07$ & $0.13 \pm 0.04$ \\
\hline
\end{tabular}

Table III. T/NT ratio of ${ }^{99} \mathrm{Tc}^{\mathrm{m}}$-(HYNIC-PI) (tricine) (TPPTS) in tumor-bearing mice.

\begin{tabular}{|c|c|c|c|c|c|}
\hline \multirow[b]{2}{*}{ Ratio } & \multicolumn{5}{|c|}{ Time } \\
\hline & $30 \mathrm{~min}$ & $60 \mathrm{~min}$ & $120 \mathrm{~min}$ & $240 \mathrm{~min}$ & $360 \mathrm{~min}$ \\
\hline Tumor/muscle (T/NT) & $7.49 \pm 1.83$ & $4.14 \pm 0.69$ & $5.54 \pm 1.40$ & $9.67 \pm 2.88$ & $5.75 \pm 1.60$ \\
\hline Tumor/blood (T/NT) & $2.85 \pm 0.41$ & $1.80 \pm 0.16$ & $2.91 \pm 0.36$ & $5.85 \pm 1.81$ & $4.00 \pm 0.73$ \\
\hline
\end{tabular}
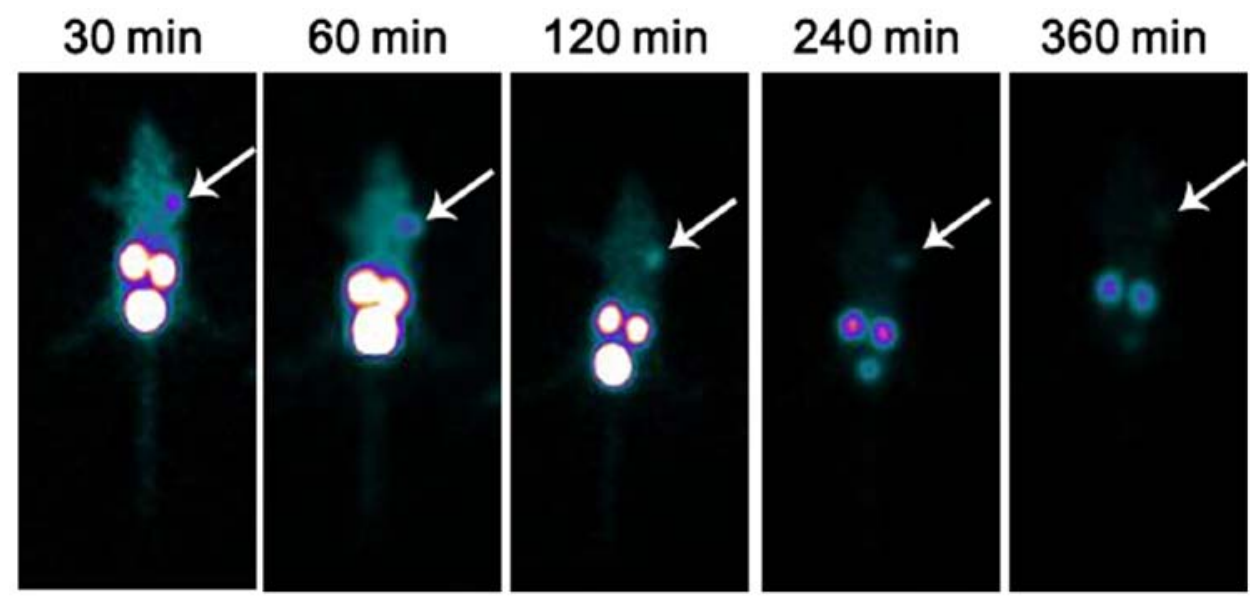

Figure 5. Imaging of ${ }^{99} \mathrm{Tc}^{\mathrm{m}}$-(HYNIC-PI) (tricine) (TPPTS) in tumor-bearing mice. SPECT showed that the imaging of the mouse outline was clearly seen at $30 \mathrm{~min}$. The radioactivity uptake in kidneys and bladder was very high. Known tumor sites showed rapid and intense tracer accumulation. The tumor imaging quality was high at $1 \mathrm{~h}$ and then gradually became unclear. By $6 \mathrm{~h}$, the imaging was blurred.

excreted by the kidney. The in vivo distribution of tumorbearing mice was similar to that of the normal mice. The tumor T/NT was higher and reached $(9.67 \pm 2.88)$ at $4 \mathrm{~h}$. All the data are shown in Tables I, II and III. SPECT showed that the imaging of the mouse outline was clearly observed at $30 \mathrm{~min}$. The radioactivity uptake in the kidneys and bladder was also high. Tumor sites showed rapid and intense tracer accumulation. The tumor imaging quality was high at $1 \mathrm{~h}$ and then gradually decreased. By $6 \mathrm{~h}$, the imaging was blurred (Fig. 5).

\section{Discussion}

Current approaches, including surgery, chemotherapy and radiotherapy, are still insufficiently effective in treating tumors because of their invasive, aggressive growth profile, as well 
as the complex mechanisms involved in cancer development. New anticancer strategies are thus urgently required. Targeted cancer gene therapy is of unquestionable importance for improving therapeutic efficacy and minimizing adverse effects $(13,14)$. Although current gene therapy is mainly limited by the lack of efficient gene delivery vehicles, the recent development of cell penetrating peptides (CPPs) has overcome these barriers, leading to novel tumor-specific molecular therapeutics. The protein transduction domains (PTD) $(15,16)$, can also facilitate cytoplasmic and nuclear delivery of a conjugated cargo and have attracted much interest.

Importantly, the non-toxic mechanism of cell penetration allows for the safe and effective systemic delivery of cancer therapeutics, whereas when the PTDs are applied in antitumor therapy, they transfer the exogenous genes or drugs not only into cancer cells but also into normal cells, thus damaging these cells. Therefore, it is desirable to find a tumor cellspecific targeted vector to solve this problem. Recently, several laboratories have selected peptides as a novel vehicle to target the specific cells or tissues (17-19). This strategy offers an approach to treat cancer in a specific manner by delivering optimized protein or therapeutic cargo to achieve anticancer therapies. During the past decade, numerous reports and patents of peptides have been published in the field of cancer therapy, demonstrating their potential for the treatment of leukemia and breast, lung, pancreatic, ovarian and colon cancers (20-27). However, there has been no peptide vehicle for breast cancer, so our team was devoted to selecting a breast cancer-specific peptide and evaluating its potential as a specific delivery system for tumor targeting therapy. We co-cultured the pC89 phage display library with MDA-MB-231 TNBC cells for the selection of a peptide with tumor cellular specificity. In our results, we found four peptides but CASPSGALRSCpresenting phage, named PI, was the best candidate clone with the highest specificity for MDA-MB-231 cells and was thus selected for the following cellular binding assay (12). For comparison, RGD-integrin binding phage was introduced as a control, because it is known to be recognized and internalized by many types of human cells $(28,29)$.

The affinity experiment suggested that PI is a new type of transmembrane peptide with MDA-MB-231 cell specificity. The notable cellular specificity of PI, the combination of it as a vector of therapeutic protein, may be a practical way to improve targeting efficiency in tumor therapy. In this report, with the aim of investigating the delivery potency of PI, GST was introduced as an exogenous protein which was fused with PI and acted as a marker to assess the protein transduction ability of PI in vitro. PI can successfully allow GST to penetrate into the cytoplasm and maintain the non-degradation of exogenous proteins for $\geq 72 \mathrm{~h}$. Significant immunofluorescence signals of PI/GST were observed in MDA-MB-231 cytoplasm, but there were no signals of GST in MDA-MB-231 cells, indicating that PI can deliver exogenous protein of $\geq 26 \mathrm{kDa}$ size into MDA-MB-231 cells. Moreover, this transduction procedure is cell-specific, as confirmed by co-culturing PI /GST with different human breast cancer cell lines. No signal of PI/GST was observed in MDA-MB-435 cells. This result revealed that PI facilitated the delivery of exogenous molecules across the cell membrane. Furthermore, the presence of intact PI/GST fusion protein was detected around the cell nucleus, which suggested the nucleophilicity of PI as a delivery system. This conjecture was confirmed by observing the transportation of PI/GST into the cell nucleus during the terminal $24 \mathrm{~h}$ of incubation. The nucleus-localized nature of PI thus provides a promising method to develop a vehicle to deliver therapeutic proteins or polynucleotides to the target site and be effective. Therefore, we supposed that PI can deliver drug proteins for cancer targeting therapy in a cell-specific manner. However, whether it localizes tumors and how it metabolizes in vivo remain unknown. To determine its biodistribution in vivo, we marked PI with ${ }^{99 \mathrm{~m}} \mathrm{Tc}$ as a tracer. As expected, ${ }^{99 \mathrm{~m}} \mathrm{Tc}$ - HYNIC-PI was mainly eliminated through the kidneys with some residual activity. Radioactivity was reduced to near background levels at $6 \mathrm{~h}$ after injection. In MDA-MB-231 cell-bearing nude mice, tumors showed moderately increased activity compared to the background, allowing the detection of PI by imaging and revealing tumor-targeting localization. Free ${ }^{99 m}$ Tc-HYNICexpression of the target in normal organs was less intense. When imaging with ${ }^{99 \mathrm{~m}} \mathrm{Tc}-\mathrm{HYNIC}$, these tissues took up the radionuclide because of its negative charge. ${ }^{99 \mathrm{~m}} \mathrm{Tc}-\mathrm{HYNIC}-\mathrm{PI}$ had good bioavailability with adequate blood activity and minor tissue activity in normal organs. Target mediated drug delivery may be further studied with PI due to its tumorspecific enrichment. Studies have validated the potential of PI as a vehicle for safe delivery, effectively killing proteins in the target cells. In many studies, herpes simplex virus thymidine kinase/ganciclovir suicide gene system (HSV-TK/GCV) has shown an effective role in cancer therapy (30). However, using the HSV-TK/GCV system alone has limitations, including the division of cells limiting the killing effect, and the inability of targeting tumors with distant metastases. Therefore, in our experiment, we used the specific peptide PI delivering HSV-TK suicide gene transfer, combined with systemically administered ganciclovir (GCV), as therapeutic proteins delivered into target cells. When co-cultured with MDA-MB-231 cells, PI-HSV-TK itself did not present any cytotoxic effects, but when cultured with GCV, PI-TK/ GCV was able to obviously inhibit the proliferation of MDA-MB-231 cells and exhibited a dose-dependent efficacy and an $\mathrm{IC}_{50}$ value of $152.64 \mu \mathrm{g} / \mathrm{ml}$ (data not shown). Our study also showed that death increased when the 'suicide gene' product TK was fused with PI. This result suggests that PI delivered the HSV-TK in a way that allowed it to localize in the nucleus and exhibit its target-killing effect and may be an efficient drug delivery vector for MDA-MB-231 TNBC breast cancer targeting therapy. However, the mechanism involved remains unclear.

In a previous study, we confirmed that the specificity of PI combined with 231 cells was not related to the expression of ER and P53 or MHC-I. In other preliminary research using our phage library, the lipid rafts/caveolin pathway inhibitors nystatin and MDA-MB-231 breast cancer cells were co-cultured and then added to the PI. Fluorescence microscopy and flow cytometry analysis showed lower and weaker fluorescent signal than that with cells that were not treated with nystatin. This finding suggests that nystatin has certain inhibitory effects for the combination of PI and MDA-MB-231 breast cancer cells. We preliminarily speculated that mechanism of PI transducing into MDA-MB-231 cells was mediated 
by nest protein, which depended on the Caveolae endocytosis mechanism, however, further research is still necessary.

In conclusion, this study supports that the capacity of PI to deliver molecules into target cells and indicate its therapeutic potential in individual therapy. PI may be an efficient drug delivery vectors for TNBC cancer targeting therapy. However, our knowledge on this interesting phenomenon is limited, and the exact transduction mechanism is unknown. Further work is needed to identify the target molecule.

\section{Acknowledgements}

We thank Mr. Bo Yang for reviewing the manuscirpt. This study was supported by grants (nos. 30860330 and 30460142) of National Natural Science Foundation of China, 'The applied basic research projects in Yunnan Province' (no. 2009CC023) and was a major scientific research project of Yunnan Provincial Education Fund (ZD2013005).

\section{References}

1. Aguas F, Martins A, Gomes TP, de Sousa M and Silva DP Portuguese Menopause Society and Portuguese Gynaecology Society: Prophylaxis approach to a-symptomatic post-menopausal women: Breast cancer. Maturitas 52 (Suppl 1): S23-S31, 2005.

2. Dumitrescu RG and Cotarla I: Understanding breast cancer risk - where do we stand in 2005? J Cell Mol Med 9: 208-221, 2005.

3. O'Toole SA, Beith JM, Millar EK, West R, McLean A, Cazet A, Swarbrick A and Oakes SR: Therapeutic targets in triple negative breast cancer. J Clin Pathol 66: 530-542, 2013.

4. Hurley J, Reis IM, Rodgers SE, Gomez-Fernandez C, Wright J, Leone JP, Larrieu R and Pegram MD: The use of neoadjuvant platinum-based chemotherapy in locally advanced breast cancer that is triple negative: Retrospective analysis of 144 patients. Breast Cancer Res Treat 138: 783-794, 2013.

5. Al-Ejeh F, Shi W, Miranda M, Simpson PT, Vargas AC, Song S, Wiegmans AP, Swarbrick A, Welm AL, Brown MP, et al: Treatment of triple-negative breast cancer using anti-EGFRdirected radioimmunotherapy combined with radiosensitizing chemotherapy and PARP inhibitor. J Nucl Med 54: 913-921, 2013.

6. Rodler E, Korde L and Gralow J: Current treatment options in triple negative breast cancer. Breast Dis 32: 99-122, 2010.

7. De Laurentiis M, Cianniello D, Caputo R, Stanzione B, Arpino G, Cinieri S, Lorusso V and De Placido S: Treatment of triple negative breast cancer (TNBC): Current options and future perspectives. Cancer Treat Rev 36 (Suppl 3): S80-S86, 2010.

8. Kummar S, Kinders R, Gutierrez ME, Rubinstein L, Parchment RE, Phillips LR, Ji J, Monks A, Low JA, Chen A, et al: Phase 0 clinical trial of the poly (ADP-ribose) polymerase inhibitor ABT-888 in patients with advanced malignancies. J Clin Oncol 27: 2705-2711, 2009.

9. Helleday T, Bryant HE and Schultz N: Poly (ADP-ribose) polymerase (PARP-1) in homologous recombination and as a target for cancer therapy. Cell Cycle 4: 1176-1178, 2005.

10. Koren E and Torchilin VP: Cell-penetrating peptides: Breaking through to the other side. Trends Mol Med 18: 385-393, 2012.

11. Ryu JS, Kuna M and Raucher D: Penetrating the cell membrane, thermal targeting and novel anticancer drugs: The development of thermally targeted, elastin-like polypeptide cancer therapeutics. Ther Deliv 5: 429-445, 2014.

12. Dong J, Liu W, Jiang A, Zhang K and Chen M: A novel peptide, selected from phage display library of random peptides, can efficiently target into human breast cancer cell. Chin Sci Bull 53: 860-867, 2008
13. Zadeh G, Qian B, Okhowat A, Sabha N, Kontos CD and Guha A: Targeting the Tie2/Tek receptor in astrocytomas. Am J Pathol 164: 467-476, 2004.

14. De Palma M, Venneri MA and Naldini L: In vivo targeting of tumor endothelial cells by systemic delivery of lentiviral vectors. Hum Gene Ther 14: 1193-1206, 2003.

15. Green M and Loewenstein PM: Autonomous functional domains of chemically synthesized human immunodeficiency virus tat trans-activator protein. Cell 55: 1179-1188, 1988.

16. Frankel AD and Pabo CO: Cellular uptake of the tat protein from human immunodeficiency virus. Cell 55: 1189-1193, 1988.

17. Du B, Han H, Wang Z, Kuang L, Wang L, Yu L, Wu M, Zhou Z and Qian M: targeted drug delivery to hepatocarcinoma in vivo by phage-displayed specific binding peptide. Mol Cancer Res 8: $135-144,2010$.

18. Li ZJ, Wu WKK, Ng SSM, Yu L, Li HT, Wong CC, Wu YC, Zhang L, Ren SX, Sun XG, et al: A novel peptide specifically targeting the vasculature of orthotopic colorectal cancer for imaging detection and drug delivery. J Control Release 148: 292-302, 2010.

19. Zhang L, Yin G, Yan D, Wei Y, Ma C, Huang Z, Liao X, Yao Y, Chen $X$ and Hao B: In vitro screening of ovarian tumor specific peptides from a phage display peptide library. Biotechnol Lett 33: 1729-1735, 2011.

20. Yu Z, Wu J, Wu S, Jia P, Tong Y, Wu X and Wang Y: A recombinant cell-permeable p53 fusion protein is selectively stabilized under hypoxia and inhibits tumor cell growth. Cancer Lett 279: 101-107, 2009.

21. Hu M, Wang J, Chen P and Reilly RM: HIV-1 Tat peptide immunoconjugates differentially sensitize breast cancer cells to selected antiproliferative agents that induce the cyclindependent kinase inhibitor p21WAF-1/CIP-1. Bioconjug Chem 17: 1280-1287, 2006

22. Bitler BG, Menzl I, Huerta CL, Sands B, Knowlton W, Chang A and Schroeder JA: Intracellular MUC1 peptides inhibit cancer progression. Clin Cancer Res 15: 100-109, 2009.

23. Massodi I, Bidwell GL III, Davis A, Tausend A, Credit K, Flessner M and Raucher D: Inhibition of ovarian cancer cell metastasis by a fusion polypeptide Tat-ELP. Clin Exp Metastasis 26: 251-260,2009.

24. Bidwell GL III, Davis AN and Raucher D: Targeting a c-Myc inhibitory polypeptide to specific intracellular compartments using cell penetrating peptides. J Control Release 135: 2-10, 2009 .

25. Harada H, Hiraoka M and Kizaka-Kondoh S: Antitumor effect of TAT-oxygen-dependent degradation-caspase-3 fusion protein specifically stabilized and activated in hypoxic tumor cells. Cancer Res 62: 2013-2018, 2002.

26. Takada Y, Singh S and Aggarwal BB: Identification of a p65 peptide that selectively inhibits NF-kappa B activation induced by various inflammatory stimuli and its role in down-regulation of NF-kappaB-mediated gene expression and up-regulation of apoptosis. J Biol Chem 279: 15096-15104, 2004.

27. Tan M, Lan K-H, Yao J, Lu CH, Sun M, Neal CL, Lu J and Yu D: Selective inhibition of ErbB2-overexpressing breast cancer in vivo by a novel TAT-based ErbB2-targeting signal transducers and activators of transcription 3-blocking peptide. Cancer Res 66: 3764-3772, 2006.

28. Miller WH, Alberts DP, Bhatnagar PK, Bondinell WE, Callahan JF, Calvo RR, Cousins RD, Erhard KF, Heerding DA, Keenan RM, et al: Discovery of orally active nonpeptide vitronectin receptor antagonists based on a 2-benzazepine Gly-Asp mimetic. J Med Chem 43: 22-26, 2000.

29. Zhao H, Wang J-C, Sun Q-S, Luo C-L and Zhang Q: RGD-based strategies for improving antitumor activity of paclitaxel-loaded liposomes in nude mice xenografted with human ovarian cancer. J Drug Target 17: 10-18, 2009.

30. Burrows FJ, Gore M, Smiley WR, Kanemitsu MY, Jolly DJ, Read SB, Nicholas T and Kruse CA: Purified herpes simplex virus thymidine kinase retroviral particles: III. Characterization of bystander killing mechanisms in transfected tumor cells. Cancer Gene Ther 9: 87-95, 2002. 